\title{
UMA ANÁLISE DAS NOÇÕES DE ÁREA E PERÍMETRO À LUZ DA TEORIA ANTROPOLÓGICA DO DIDÁTICO
}

\author{
AN ANALYSIS OF THE NOTIONS OF AREA AND PERIMETER \\ IN LIGHT OF THE ANTHROPOLOGICAL THEORY OF DIDACTICS \\ CINTIA AP. BENTO DOS SANTOS* \\ DEBORA VIRGILIA CANNE**
}

\section{RESUMO}

0 presente artigo tem por objetivo apresentar alguns resultados de uma pesquisa de Mestrado Profissional em Ensino de Ciências e Matemática em que foram realizadas analises a luz da Teoria Antropológica do Didático em relação às tarefas que focavam as noções de área e perímetro nos Cadernos dos Alunos e Professores dos anos finais do Ensino Fundamental da Secretaria Estadual de Educação de São Paulo, para este artigo escolhemos apresentar as tarefas de $9^{\circ}$ ano. Trata-se de uma pesquisa qualitativa com método de análise documental em que por meio de uma grade elaborada com base em nosso quadro teórico nos permitiu investigar como são propostas as noções de área e perímetro. Ao final, um dos indicativos é que esta teoria nos possibilita uma ferramenta de análise contribuindo para que professores compreendam melhor as dificuldades dos educandos.

Palavras-chave: Anos finais do Ensino Fundamental. Teoria antropológica do didático. Área e perímetro.

\section{ABSTRACT}

The purpose of this article is to present some results of a Professional Master's research in Science and Mathematics Teaching in which analyzes were carried out in the light of the Anthropological Theory of Didactics in relation to the tasks that focused on the notions of area and perimeter in the Students' Notebooks and Teachers from the final years of elementary school at the São Paulo State Department of Education, for this article we chose to present the 9th grade assignments. It is a qualitative research with documentary analysis method in which, through a grid elaborated based on our theoretical framework, allowed us to investigate how the notions of area and perimeter are proposed. In the end, one of the indications is that this theory provides us with an analysis tool that helps teachers better understand the students' difficulties.

Keywords: Final years of Elementary School. Anthropological theory of didactics. Area and perimeter.

\footnotetext{
* Doutora em Ensino de Ciências e Matemática. Universidade Cruzeiro do Sul. E-mail: cintia.santos@cruzeirodosul.edu.br. Orcid: https://orcid.org/ 0000-0001-8604-2890

** Mestra em Ensino de Ciências e Matemática. Secretaria Estadual de Educação SP. E-mail: debora.canne@gmail.com.Orcid: https://orcid.org/ 0000-0003-3228-8056
} 


\section{CONTEXTO DE PESQUISA E PROCEDIMENTOS DE ANÁLISE}

No cenário acadêmico, muito se tem discutido sobre as noções de área e perímetro, que, comumente, são noções matemáticas aparentemente simples aos olhos de professores, no entanto, de difícil entendimento conceitual para alunos.

Atualmente, a Base Nacional Comum Curricular (2017), apresenta as noções de área e perímetro na unidade temática Grandezas e Medidas. 0 presente documento, de carácter normativo, prevê que 0 ensino de área e perímetro deve ocorrer desde os anos iniciais do Ensino Fundamental.

Pesquisadores como Baltar (1996), Facco (2003), Brito (2003), Melo (2003) e Santos (2008), indicam as dificuldades no contexto educativo, no que se refere à institucionalização quanto às noções de área e perímetro.

0 trabalho com área e perímetro no Ensino Fundamental, segundo Lima e Bellemain (2010), por um período duradouro, foi marcado pela ênfase no ensino de fórmulas relacionadas às áreas das figuras geométricas usuais (triângulo, quadrado, retângulo, trapézio, paralelogramo e losango), e também, das conversões de unidades de medidas de área e comprimento (converter metros (m) em centímetros (cm), metros $(\mathrm{m})$ em quilômetros $(\mathrm{km})$, converter resultados obtidos de áreas e volumes).

Segundo Lima e Bellemain (2010), é perceptível a insistência na repetição de exercícios que valorizam a utilização das fórmulas para os cálculos de área e conversões de unidades. Esses tipos de exercícios têm se mostrado ineficazes e geradores de entraves futuros para a aprendizagem dos alunos, causando uma grande confusão entre as noções de área e perímetro. Notadamente, os alunos tentam decorar as fórmulas de cada figura, sem saber relacioná-la com os cálculos, confundem área com o perímetro da figura, não sabendo diferenciar uma da outra, ou seja, não há uma compreensão conceitual quanto a essas duas noções.

Lima e Bellemain (2010), afirmam que no ensino e aprendizagem de medidas é comum a confusão entre as noções de área e de perímetro por parte dos alunos, pois, muitas vezes, eles empregam relações equivocadas, como ao compararem duas superfícies. Esses autores concluem que aquela que possui maior área, necessariamente também terá maior perímetro e vice-versa.

Uma das possíveis justificativas para essas conclusões por parte do aluno, pode estar relacionada a ausência de situações-problema em que essas duas concepções estejam presentes, ou seja, atividades que explorem situações de comparação em que duas figuras tenham o mesmo perímetro e áreas diferentes, mesma área e perímetros diferentes, ou perímetros e áreas iguais.

Portanto, fica evidente a necessidade de um trabalho conciso com estas noções matemáticas e sem, necessariamente, a preocupação de aplicação das fórmulas desde os anos iniciais, para que os outros professores possam dar continuidade aos conteúdos referentes à área e perímetro nos anos de institucionalização deste conhecimento matemático que os alunos devem percorrer.

Em termos de institucionalização de um conhecimento matemático, é importante olhar os materiais institucionais, para saber como eles apresentam determinada noção matemática aos alunos, e como indicam ao professor 0 trabalho com as tarefas propostas.

Levando em consideração 0 contexto mencinado e nossas inquietaçães em relação aos processos de ensino e aprendizagem sobre as noções de área e perímetro desenvolvemos uma investigação de caráter documental, fruto de uma pesquisa realizada em um Mestrado Profissional em Ensino de Ciências e Matemática, que pode ser verificada em Canne (2015).

A pesquisa foi desenvolvida no âmbito do Grupo de estudos e pesquisas em Didática e Metodologias em Educação Matemática, tendo por objetivo responder a seguinte questão de pesquisa: 
"Como são institucionalizadas as noções de área e perímetro de acordo com o Currículo do Estado de São Paulo para os anos finais do Ensino Fundamental?"

Cabe destacar que este material curricular é disponibilizado nas escolas estaduais de São Paulo para alunos e professores, e também disponível para o professor da Rede Pública Estadual, no site da Secretaria Estadual da Educação, na opção "São Paulo faz Escola". Destacamos, ainda, que os documentos em análise estão vigentes na rede estadual de ensino do estado de São Paulo desde 2008.

Para as nossas análises foram selecionadas as Situações de Aprendizagem referentes ao uso das noções de área e perímetro, presentes nos Cadernos dos Alunos, bem como as respectivas orientações disponíveis no Caderno do Professor.

Com isso, montamos uma grade de análise, com aporte teórico em Chevallard (Teoria Antropológica do Didático), Bosch e Chevallard (Objetos ostensivos e não ostensivos).

Para procedermos às análises, utilizamos a grade adiante, que nos permite identificar parte das organizações praxeológicas existentes, ou seja, o bloco prático: tipos de tarefas e técnicas, considerando que os Cadernos de Matemática dos Alunos e dos Professores, são fornecidos pelo Governo do Estado de São Paulo para serem empregados em sala de aula, e estão em conformidade com 0 Currículo do Estado de São Paulo.

Quadro 1 - Modelo de grade de análise

\begin{tabular}{|l|}
\hline Tarefa \\
\hline Técnica \\
\hline Ostensivos manipulados na técnica/ Tecnologia \\
\hline Não ostensivos evocados na técnica / Teoria \\
\hline
\end{tabular}

Fonte: Adaptada de FONSECA, 2011, p. 7.

Com base na organização desta grade de análise, identificamos cada item do quadro de cada atividade selecionada, referente à noção de área e perímetro à luz da teoria escolhida para essas análises. A Teoria Antropológica do Didático afirma que cada tarefa tem pelo menos uma técnica, e a tecnologia e teoria garantem a existência dessa técnica.

A luz da Teoria Antropológica do Didático de Chevallard (1996), vamos identificar as praxeologias ou organizações praxeológicas de cada tarefa (tarefa, técnica, tecnologia, teoria). Para justificarem cada técnica, Bosch e Chevallard (1999) apoiam-se nos objetos ostensivos e não ostensivos manipulados em cada técnica.

Para este artigo apresentaremos a análise de algumas tarefas que foram objeto de estudo da ação não há uma abordagem explicita para o estudo de área e perímetro, porém estas noções matemáticas aparecem como articuladores de outros objetos matemáticos.

\section{ALGUNS ASPECTOS DA TEORIA ANTROPOLÓGICA DO DIDÁTICO}

A Teoria Antropológica do Didático considera os objetos matemáticos, não como existentes em si, mas como entidades que emergem de sistemas de práticas que existem em dadas instituiçõos. Esses sistemas ou praxeologias são descritos em termos de tarefas específicas (exercícios) daquele objeto, das técnicas que permitem resolvê-las e através dos discursos que servem para explicar e justificar as técnicas. 
Conforme mencionamos anteriormente, nosso estudo toma como aporte teórico a Teoria do Antropológico do Didático (TAD), de Chevallard (1996), que situa a atividade matemática e, consequentemente, a atividade de estudo em Matemática no conjunto das atividades humanas e das instituições sociais: "[..] falar validamente de Didática da Matemática, por exemplo, supõe falar de certos objetos distintos - a Matemática, de início, e, em seguida, solidariamente os alunos, os professores, os livros, etc." (CHEVALLARD, 1998, p. 91). Segundo o pesquisador "A TAD ajuda-nos a pensar a dimensão técnica e instrumental do trabalho matemático, que, nas análises didáticas, é frequentemente deixada no segundo plano, em proveito de análises de natureza mais conceitual". (CHEVALLARD, 1996, p. 9)

0 ponto de partida dessa teoria é que "tudo é objeto". 0 autor distingue, no entanto, os tipos de objetos específicos: instituições (I), pessoas $(X)$ e as posições que ocupam as pessoas nas instituições, de que trataremos mais adiante.

Segundo Chevallard (1996), para determinado tema de estudo, deve-se considerar, em primeiro lugar, a realidade Matemática que pode ser construída, a qual chama de Praxeologia Matemática ou Organização Matemática (OM) e, em segundo lugar, a maneira como essa realidade pode ser estudada, que será denominada Organização Didática (OD).

De acordo com o autor, os elementos primitivos são: Instituição (I), Pessoa (X) e Objeto (0), e fazem parte da relação institucional e pessoal ao objeto. 0 objeto é toda entidade, material ou não, que existe para ao menos um indivíduo. Os objetos (0) são os elementos de base da teoria, e como exemplos de objetos matemáticos, podemos citar o quadrado, a noção de perímetro, área, a equação do $2^{\circ}$ grau, entre outros.

A partir das noções primitivas, Chevallard (1996) define relação pessoal $(R(X, 0))$ da pessoa $(X)$ ao objeto $(0)$, e analogamente define a relação institucional de $(I)$ a $(0)$, denotada $(R(I, 0))$. Um objeto (0) do saber existe na medida em que uma pessoa (X) ou uma instituição (I) o reconhece e 0 aceita como existente, ou seja, se existir uma relação pessoal de $(X)$ com o objeto (0), ou instituição (I) com 0 objeto $(0)$. A pessoa $(X)$ ou a instituição $(I)$ conhece $(0)$ se existir $R(X, 0)$. A relação pessoal de $(0)$ determina a maneira como $(X)$ conhece $(0)$. De maneira análoga, define uma relação institucional de (I) a (0), denotada $R(I, 0)$, que exprime o reconhecimento do objeto (0) pela instituição (I).

Para Chevallard (1996):

Os objetos ocupam, contudo, uma posição privilegiada: são o "material de base" da construção teórica considerada. Da mesma maneira que, no universo matemático contemporâneo, fundado na teoria dos conjuntos, tudo é conjunto (os próprios números inteiros são conjuntos), assim, também, no universo que estou a considerar, todas as coisas são objetos. As pessoas X e as Instituições I, bem como as restantes entidades que serei levado a introduzir, são pois objetos de um tipo particular. (CHEVALLARD, 1996, p. 127)

Nesse sentido, o autor introduz a noção de conhecimento, ou seja, conhecer um objeto é, tanto para uma instituição como para uma pessoa, ter uma relação com esse objeto. De acordo com esse autor, a instituição (I) pode ter várias representações, uma escola é uma instituição, tal como é uma 
sala de aula; mas existe igualmente a instituição "trabalhos orientados", a instituição "cursos", a instituição "família". A vida cotidiana é uma instituição (num dado meio social), o mesmo acontecendo ao estado amoroso (numa dada cultura), etc.

Bosch (2000) segue a linha de Chevallard, e juntos desenvolveram uma pesquisa usando as praxeologias, complementando com os estudos dos objetos ostensivos e não ostensivos.

Segundo a Teoria Antropológica do Didático, na cultura escolar, ocorre o desenvolvimento de uma infinidade de atividades de estudo, onde é verificada a existência de uma pluralidade de registros das mesmas. Esses registros podem se apresentar sob a forma escrita, gráfica, verbal, gestual, etc., e são denominados objetos ostensivos, visto que a Teoria Antropológica assume o seu valor semiótico (simbólico). Assim, podemos dizer que as linguagens dos objetos ostensivos podem ser escritural (linguagem escrita), figural (representação de figuras), verbal (quando a pessoa fala ou explica determinado assunto), gestual (ao gesticular, por exemplo, a forma de uma parábola, de uma reta), gráfica (utilização de gráficos), entre outras.

0 modelo proposto pela TAD estabelece uma distinção dentro do conjunto de objetos que compõem os elementos das organizações matemáticas: as tarefas, as técnicas, as tecnologias e as teorias são feitas de objetos ostensivos e de objetos não ostensivos.

Segundo Bosch (2000), a palavra "ostensivo" tem sua origem na palavra latina ostendere, que é tudo aquilo que se mostra, que se percebe, que se vê e ouve, dotado de certa materialidade, como as escritas, os gráficos, os desenhos, os experimentos, os sons, os gestos, os discursos, dentre outros, que faz parte da cultura humana corrente e que pode ser manipulado'.

Os objetos não ostensivos são aqueles que existem institucionalmente, mas que não podem ser percebidos, não se mostram por si mesmos. Exemplos deles são as ideias, os conceitos, as crenças. Esses objetos emergem da manipulação de objetos ostensivos, que será sempre controlada por objetos não ostensivos.

A dialética entre os ostensivos e não ostensivos provavelmente é conduzida pelo professor por meio dos registros oral e escrito; por exemplo, ao registrar no quadro a//b, suponhamos que ele diga para os alunos que se trata do conceito de paralelismo (não ostensivo) entre as retas a e b.

Quando 0 professor anota, por exemplo, " $3 x$ é a medida da largura e $(2 x+1)$ é a medida do comprimento de um retângulo, quando representa a medida da área desse retângulo", no estudo de expressões, ele está fazendo um registro algébrico que requer a manipulação de ostensivos escritos, como letras e números. Pode utilizar também registros orais, como, por exemplo, ao afirmar que a área do retângulo é calculada multiplicando a medida da largura pela medida do seu comprimento; por outro lado, é necessário evocar o conceito de área do retângulo (não ostensivo) para poder realizar a tarefa.

Em qualquer atividade humana, mais especificamente, em toda atividade Matemática, conforme Bosch e Chevallard (1999) existe a co-ativação de objetos ostensivos e não ostensivos. Na abordagem antropológica, podemos dizer que o cumprimento de toda tarefa envolve necessariamente a manipulação de ostensivos regulados pelos não ostensivos (ALMEIDA, 2012).

$\mathrm{Na}$ figura 1 apresentamos um exemplo para elucidar esta abordagem.

1 Manipulado: designa os diversos usos possíveis, pelo ser humano, dos objetos ostensivos, ou seja, aqueles objetos que podem ser percebidos, vistos. (BOSCH e CHEVALARD, 1999). 
Figura 1 - Desenho esquemático de polígonos inscritos no círculo
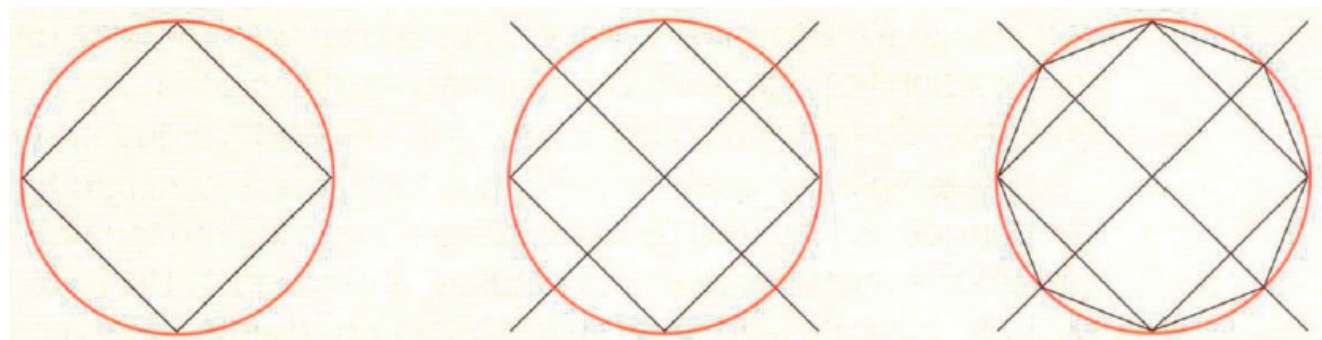

Fonte: ALMEIDA, 2012, p. 105.

Segundo Almeida (2012), para a resolução da questão, os alunos utilizaram os seguintes ostensivos: desenho esquemático de polígonos inscritos no círculo, onde utilizaram as técnicas de observar e identificar suas estruturas; a escrita, com o emprego da técnica de nomear os polígonos e pontuar as diferenças entre ambas; a oralidade, com a técnica de interagir e argumentar coletivamente, e com o professor, sobre o tema, além de apresentar os resultados dos cálculos para a classe, percebendo quanto maior a quantidade de lados de polígono, mais próximo do comprimento da circunferência o valor estará. Ao manipularem esses ostensivos, os alunos e o professor trouxeram à superfície os objetos não ostensivos.

Os alunos, ao manejarem os objetos ostensivos da tarefa, observaram que ao aumentar a quantidade de lados dos polígonos, mais próximo do valor do comprimento da circunferência chegará e esse procedimento é infinito. Assim surgiu, então, a ideia da exaustão e uma maneira também de se aproximar do valor numérico de "pi" e sua relação com os cálculos de comprimento da circunferência e área do círculo.

Bosch e Chevallard (1999) delimitam a noção de tarefa em Matemática, o que diferencia a atividade matemática das demais atividades humanas, pois, diante de uma tarefa, é preciso saber como resolvê-la. Esse "como resolver a tarefa" é o que impulsiona a praxeologia. É preciso ter ou construir uma técnica ${ }^{2}$ que deve ser justificada por uma tecnologia, a qual, por sua vez, precisa ser justificada por uma teoria.

A ostensividade que Bosch e Chevallard (1999) sustentam se refere, mais geralmente, ao conjunto dos sentidos ou significações, no qual a visão e a audição desempenham um papel fundamental. Bosch e Chevallard (1999) utilizam o termo manipulação, como já explicamos anteriormente, para designar os diversos usos possíveis de objetos ostensivos pelo homem. É através dessa manipulação concreta que se permite distinguir os objetos ostensivos dos não ostensivos.

Para Bosch e Chevallard (1999):

[..] na análise do trabalho matemático, os objetos ostensivos fazem parte do real empírico por significação. Por contraste, a presença de tal ou qual não ostensivo, numa prática determinada, só pode ser induzida ou suposta a partir de manipulação de ostensivos, institucionalmente associadas. [..] A intervenção dos não ostensivos na "práxis" manipulativa de objetos ostensivos pode proporcionar aos não ostensivos o estatuto de condição de uma manipulação adequada dos instrumentos ostensivos. (Ibidem, p. 93)

2 A técnica será utilizada como processo estruturado e metódico, às vezes algorítmico, que é um caso muito particular da técnica. 
Podemos observar, por meio das ideias dos autores, que a Teoria Antropológica do Didático (TAD) procura explicar a origem dos conceitos matemáticos (não ostensivos) e sua relação com os objetos que representam (ostensivos). De acordo com Bosch (2000), os conceitos surgem do trabalho com os ostensivos, isto é, em resposta a certas questões e tarefas em um dado entorno tecnológico-teórico.

Assim, os autores afirmam que toda prática institucional pode ser analisada de diferentes pontos de vista e de distintas maneiras, num sistema de tarefas bem definidas que se desenvolvem no fluxo da prática. A realização de toda tarefa resulta em colocar em ação uma técnica. As condições e exigências que permitem a produção e a utilização de tarefas e técnicas nas instituições implicam a existência de um discurso descritivo e justificativo das tarefas e técnicas, que se chama discurso prático-técnico. Por consequência, toda tecnologia precisa de uma justificativa, que se denomina teoria da técnica que chamaremos de discurso tecnológico-teórico.

0 significado de praxeologia pode ser traduzido por: prática calcada em conhecimentos, ou seja, na junção das palavras gregas práxis (prática, ação) e logos (fundamentos, conhecimentos). Conforme a TAD, a práxis é constituída pelas tarefas (questões/atividades) e pelas técnicas (maneira de fazer algo), e o logos, pelo discurso matemático que justifica e interpreta a prática, sendo denominados tecnologias e teorias (CHEVALLARD; BOSCH e GASCÓN, 2001), conforme detalharemos a seguir.

Uma organização praxeológica sempre surge como resposta a uma questão ou a um conjunto de questões. Desse modo, estabelece-se um processo em que se deve buscar ou criar meios para respondê-la(s). Essa questão é denominada, segundo a TAD, uma tarefa problemática ou não. A praxeologia atua justamente nesse momento, tentando encontrar uma ou mais formas de resolvê-la(s), regularmente e com sucesso (CHEVALLARD; BOSCH e GASCÓN, 2001).

Desse modo, estabelece-se um processo que para responder a uma tarefa, ou a um tipo de tarefa, é necessário que a(s) resposta(s) seja(m) segura(s), sistemática(s) e rotineira(s). Isso pode ocorrer por meio de uma ou mais técnicas. Elas devem parecer ao mesmo tempo corretas, compreensíveis e justificáveis. Além disso, necessitam possuir uma tecnologia capaz de compreender e validar a sua utilização, e uma teoria que fundamente essa tecnologia (CHEVALLARD, CHEVALLARD; BOSCH e GASCÓN, 2001). Esses elementos, agrupados, procedem a uma organização praxeológica (OP) na forma de um bloco prático-técnico, no qual encontramos o tipo de tarefa e a técnica, e um bloco tecnológico-teórico, através da tecnologia e da teoria (BOSCH e CHEVALLARD, 1999).

Para Chevallard (1996), toda atividade humana consiste em quatro conceitos básicos, que são: tarefa $(\mathrm{T})$, técnica $(\tau)$, tecnologia $(\theta)$ e teoria $(\Theta)$. Nesse sentido, pode-se dizer que toda atividade humana coloca em ação uma organização envolvendo $[T, \tau, \theta, \Theta]$, a qual Chevallard (1999) nomeia praxeologia, ou organização praxeológica.

Cabe ressaltar que, cada elemento da praxeologia é nomeado por uma letra do alfabeto grego, a saber: 0 tipo de tarefa é representado pela letra T (Tau maiúscula); a técnica, pela letra $\tau$ (tau minúscula); a tecnologia, pela letra $\theta$ (theta minúscula); e a teoria, pela letra $\Theta$ (theta maiúscula).

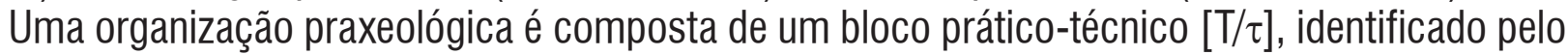
autor como um saber fazer, e de um bloco tecnológico- teórico $[\theta / \Theta]$, normalmente identificado como um saber. Nessa perspectiva, no estudo do conceito de área e perímetro, não se pergunta mais o que é área ou o que é perímetro, mas sim, quais são os tipos de tarefas a serem executadas e de técnicas envolvidas e quais são as respectivas justificativas tecnológicas e teóricas. 0 conceito de área e perímetro emerge dessas praxeologias. A ideia de perímetro emerge quando precisamos saber a medida do contorno de um determinado objeto, e a ideia de área, do espaço ocupado por tal objeto. 
É importante enfatizar que, conforme a TAD, o bloco tecnológico-teórico viabiliza a compreensão da técnica utilizada, pois, a partir dele podem-se agregar elementos para modificar a técnica empregada, se preciso for, ou até mesmo produzir uma nova técnica. Salientamos, então, que a tecnologia justifica e explica a técnica, e a teoria fundamenta a tecnologia. 0 bloco tecnológico-teórico representa nesse contexto o saber, e o bloco prático-técnico é denominado saber fazer.

Essas quatro noções (tarefa, técnica, tecnologia e teoria) permitem a modelação das práticas sociais em geral, e das atividades matemáticas em particular, desenvolvidas a seguir.

Na noção praxeológica de Tarefa, é adotado o símbolo T para representar uma tarefa identificada numa praxeologia, contendo ao menos um tipo de tarefa t. Essa noção supõe um objeto relativamente preciso; "abrir uma torneira", por exemplo, é um tipo de tarefa, mas abrir, assim isolado, não 0 é. Da mesma forma, "calcular a área de um quadrado de lado $15 \mathrm{~cm}$ " é um tipo de tarefa, mas calcular, assim isolado, é um gênero que requer um determinativo. Assim, tarefas, tipos de tarefas, gênero de tarefas não são dados da natureza; são artefatos, obras, construtos institucionais, cuja reconstrução em tal instituição é um problema inteiramente objeto da didática.

Técnica, denotada por $\tau$, é uma maneira de fazer ou realizar um tipo de tarefa T. Uma praxeologia relativa à $\mathrm{T}$ necessita de maneiras de realizar as tarefas $\tau \in \mathrm{T}$, isto é, de uma técnica (saber fazer). Assim, para um dado tipo de tarefa T existe, em geral, uma única técnica ou um conjunto de técnicas reconhecidas institucionalmente (com exceção das possíveis técnicas alternativas, que podem existir, mas em outras instituições) que permitem realizar a tarefa. Por, exemplo, uma técnica ou mais técnicas podem fracassar para 0 aluno quando a noção em jogo não é explicita, no caso não se parte numa tarefa da utilização imediata da fórmula de área ou perímetro.

Tecnologia, denotada por $\theta$, é um discurso racional (o logos) tendo por objetivo justificar a técnica $\tau$, garantindo que esta permita realizar as tarefas do tipo T. A segunda função da tecnologia é explicar, tornar compreensível a técnica. Se a primeira função "justificar a técnica" consiste em assegurar que a técnica permita alcançar o pretendido, a segunda função "explicar" consiste em expor por que é daquela maneira. É notável que as duas funções, justificação e explicação, são assumidas diferentemente por uma dada tecnologia. Tradicionalmente, no contexto matemático, a função de justificação carrega consigo a função de explicação pelo viés das exigências demonstrativas. Vejamos o exemplo: um aluno memoriza uma determinada tecnologia (teorema ou fórmula), chega a resolver certos tipos de tarefas com essa tecnologia, mas, às vezes, não sabe explicar o porquê do resultado encontrado, logo à técnica utilizada não faz sentido, pois não consegue justificar através da tecnologia.

Teoria, representada por $\Theta$, tem a função de justificar e tornar compreensível uma tecnologia $\theta$. De acordo com a TAD, podemos dizer que a teoria $\Theta$ é a tecnologia de sua tecnologia.

Uma organização praxeológica (OP) pode se apresentar em níveis diferenciados, segundo as necessidades de resolução do problema apresentado. Baseando-nos na descrição de Chevallard (1999), temos os níveis de organização praxeológica (OP) pontual, local, regional e global, que estão intimamente relacionados aos níveis de co-determinação didática. 0 nível global está situado nos níveis de co-determinação didática mais abrangentes, de civilização ou até de disciplina, pois se encontra em um patamar de atividades mais genéricas e complexas, assim como o nível regional, 
que pode se encontrar nos níveis de determinação didática área/domínio e setor. Já o nível local se encontra no âmbito do estudo em que existe um tema mais específico, e, nessa mesma direção, 0 nível pontual é voltado à resolução de um assunto/questão.

Para exemplificarmos o funcionamento desses níveis de organização praxeológica, vamos usar uma tarefa $\left(\mathrm{T}_{5}\right)$ que foi objeto de nossas análises: "0 perímetro de um quadrado é diretamente proporcional ao seu lado?"

As técnicas empregadas para a resolução da mesma constituem uma OP pontual. Dizemos que é pontual porque, para resolver essa tarefa, foi preciso lançar mão de técnicas consideradas satisfatórias para a obtenção da resposta, como testar, observar, identificar, relacionar e demonstrar, com relação direta entre o "saber fazer" e o "saber". Isso significa dizer que ocorreu a posse de certos conhecimentos e informações, ou até mesmo de saberes sobre grandezas proporcionais e perímetro, justificando, dessa forma, as técnicas empregadas, baseando-se em tecnologias e teorias presentes no currículo escolar de Matemática, materializadas através, por exemplo, dos Parâmetros Curriculares Nacionais (PCN), Currículo de Matemática do Estado de São Paulo, dos livros didáticos e Cadernos de Matemática dos Alunos e Professores.

Esclarecemos que essa OP pontual está institucionalizada na aula de Matemática do professor, ou talvez também na sala de aula de outros docentes de Matemática de outras escolas que utilizam o mesmo livro didático, o mesmo Caderno do Aluno e do Professor.

Uma OP pontual passa a ser local quando surgem novas técnicas associadas ao tipo de tarefa, como no exemplo dado, porém utilizamos as mesmas tecnologias e teorias. E conforme muda a abrangência, a OP também muda.

Com base nesta vertente teórica, nossa pesquisa teve como foco a organização praxeológica pontual, por isso, foram analisadas como são institucionalizadas as noções de área e perímetro presentes nos Cadernos de Matemática dos Alunos e Professores da rede Pública do Estado de São Paulo.

\section{ANÁLISE DAS TAREFAS À LUZ DA TEORIA ANTROPOLÓGICA DO DIDÁTICO}

Conforme dito apresentaremos as análises de algumas tarefas objeto de estudo da pesquisa, por meio de duas tarefas do $9^{\circ}$ ano em que estas noções são articuladores de outros conteúdos matemáticos.

As tarefas a seguir, de números 13 e 15, foram retiradas dos volumes 1 e 2 , do $9^{\circ}$ ano, conforme as indicações de cada quadro utilizado para as análises. A tarefa 13 se encontra na Situação de Aprendizagem 5, seus conteúdos e temas relacionados são: solução de equações do $2^{\circ}$ grau; solução geral da equação do $2^{\circ} \mathrm{grau}$; desenvolvimento da fórmula de Bháskara. Estas tarefas foram selecionadas por usar 0 cálculo de área como conteúdo articulador para a aprendizagem das equações do $2^{0}$ grau. 
Quadro 2 - Tarefa 13 (retirada do Caderno do Aluno, $9^{\circ}$ ano, v. 1, p. 46)

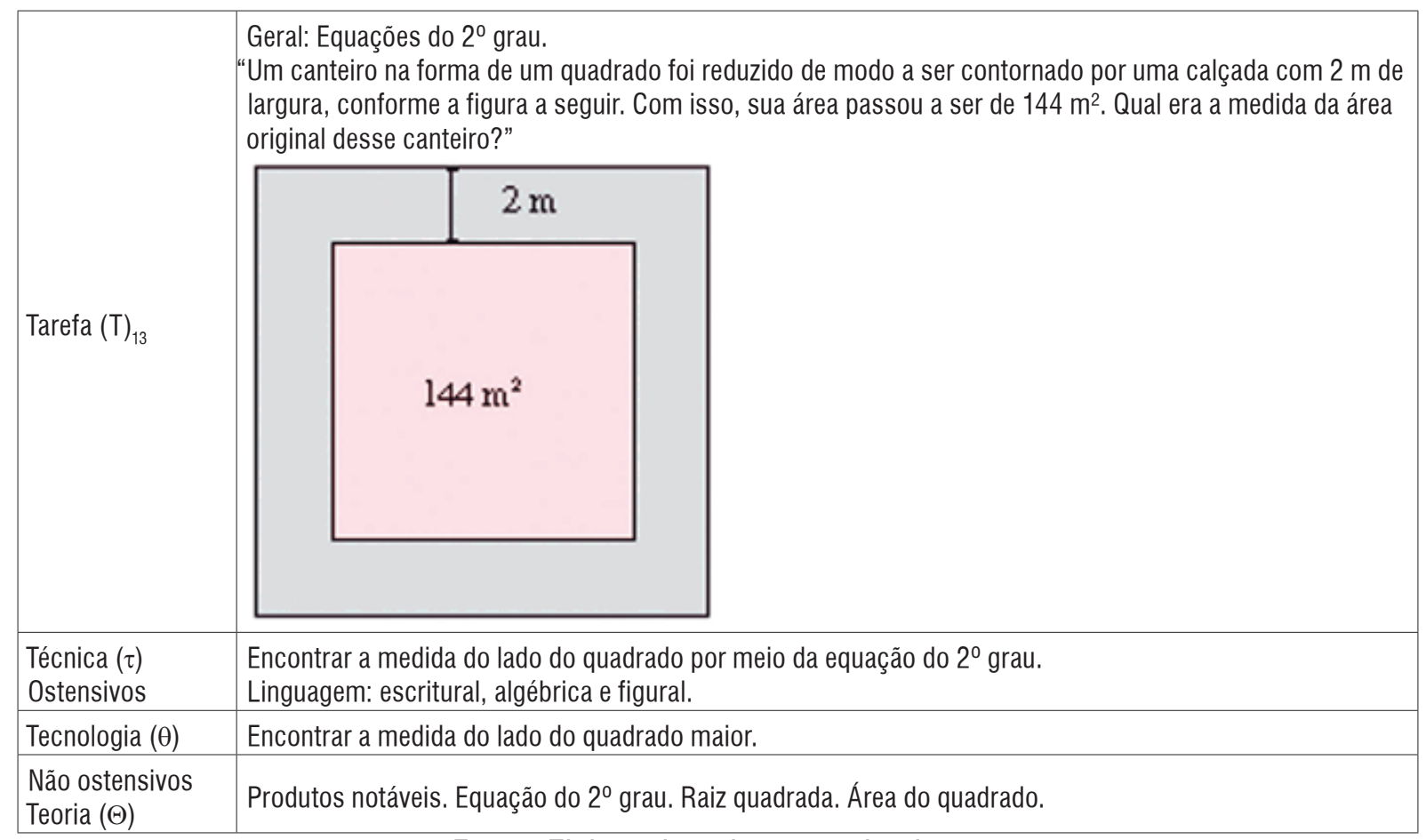

Fonte: Elaborado pelas pesquisadoras

Na resolução do tipo de tarefa T13, empregam-se conhecimentos da noção de área do quadrado, produtos notáveis, equação do $2^{\circ}$ grau e cálculo de raiz quadrada. 0 Caderno do Professor sugere apenas uma técnica, que é por meio de equação, porém, a tarefa pode ser resolvida sem a utilização de uma equação do $2^{\circ}$ grau. Uma técnica, por exemplo, que seja um procedimento de resolução própria do aluno.

Discurso prático-técnico $\left[\mathrm{T}_{13}\right.$,: 0 discurso racional aplicado na resolução deste tipo de tarefa T13 mobiliza diversos conceitos matemáticos a fim de garantir o emprego da equação do $2^{\circ}$ grau para o cálculo da área total, a partir da área mostrada na figura. 0 emprego dessa técnica leva à utilização do cálculo de raízes quadradas e aplicação da fórmula da área de um quadrado. Outra técnica que observamos é calcular a medida do lado do quadrado menor e somar $4 \mathrm{~m}$ ( $2 \mathrm{~m}$ de cada lado), obtendo $16 \mathrm{~m}$, então, a área do quadrado maior é $16 \mathrm{~m}$ vezes $16 \mathrm{~m}$, que é igual a $256 \mathrm{~m}^{2}$. Essa técnica não é sugerida no Caderno do Professor, pois o objetivo da tarefa apresentada é a aplicação da equação do $2^{0}$ grau. Os empregos dessas técnicas levam à resolução da tarefa articulados ao conceito de área de figuras planas.

Discurso tecnológico-teórico $\left[\theta_{13}, \Theta_{13}\right]:: 0$ discurso que fundamenta 0 tipo de técnica baseia-se na área do quadrado (lado x lado), ou seja, um valor x multiplicado por ele mesmo representa a área 
de um quadrado, e para encontrarmos a medida desse lado, basta calcular a raiz quadrada dessa medida. A área total também pode ser obtida por meio de uma equação do $2^{\circ} \mathrm{grau}$; se x for considerado a medida do quadrado maior, com a redução de $2 \mathrm{~m}$ de cada lado, 0 quadrado menor terá $(x-4)$ de lado. Portanto, é possível escrever a equação $(x-4)^{2}=144$. Para encontrar a solução da equação, 0 aluno poderá recorrer a várias técnicas: cálculo mental; extrair a raiz quadrada dos dois membros da igualdade; resolver usando a fórmula geral de resolução de uma equação do $2^{\circ}$ grau. Nesse sentido, 0 conceito de área e a equação do $2^{0}$ grau representam um discurso racional e justificativo da técnica que garante a realização da tarefa.

A solução encontrada no Caderno do Professor apresenta-se da seguinte forma:

Figura 2 - Solução para a tarefa 13

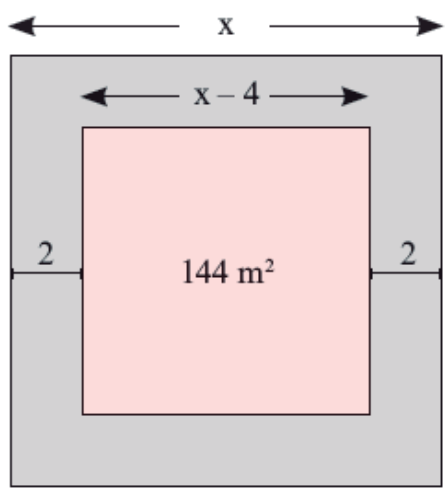

$$
\begin{gathered}
(x-4)^{2}=144 \\
\sqrt{(x-4)^{2}}=\sqrt{144} \\
(x-4)= \pm 12 \\
x-4=12 \Rightarrow \boldsymbol{x}=\mathbf{1 6} \\
x-4=-12 \Rightarrow x=-8
\end{gathered}
$$

Fonte: Caderno do Professor, 2014, v.1, p. 62.

0 valor para $x=-8$ não pode ser a medida do lado de um quadrado, mesmo satisfazendo a equação, pois a medida de lados, perímetros ou áreas de uma figura geométrica sempre são representadas por números positivos. A resposta correta será $16 \mathrm{~m}$.

0 objetivo aqui não é encontrar erros, porém, é importante que o professor fique atento às respostas dadas. Durante a resolução da equação não foi utilizada a unidade de medida metros $(\mathrm{m})$, e na apresentação do resultado final, mostrou 0 valor de $16 \mathrm{~cm}$, e na verdade, o valor da medida da área do quadrado maior seria igual a $256 \mathrm{~m}^{2}$.

A tarefa 15 faz parte das tarefas (exercícios) presentes na Situação de Aprendizagem 3, em que 0 objetivo é trabalhar as relações métricas no triângulo retângulo. 
Quadro 3 - Tarefa 15 (retirada do Caderno do Aluno, $9^{\circ}$ ano, v.2, p. 34)

\begin{tabular}{|l|l|}
\hline Geral: Relações métricas no triângulo retângulo. \\
"Um terreno tem a forma de um retângulo de catetos $30 \mathrm{~m}$ e $40 \mathrm{~m}$. Seu proprietário deseja construir uma \\
casa na região retangular representada na figura a seguir, deixando livre o restante da área."
\end{tabular}

Fonte: Elaborado pelas pesquisadoras

Na resolução do tipo de tarefa $T_{15}$, empregam-se conceitos de área de figuras planas articuladas às relações métricas no triângulo retângulo. 0 Caderno do Professor apresenta duas técnicas de resolução, que são a aplicação da fórmula da área do triângulo e a aplicação dessas relações métricas para a resolução do item "b".

Discurso prático-técnico $\left[\mathrm{T}_{15}, \tau_{15}\right]$ : o discurso racional aplicado na resolução da tarefa $\mathrm{T}_{15}$ do item "a" mobiliza apenas o conhecimento da aplicação da fórmula da área de um triângulo: $A=\frac{b . h}{2}$ . Essa área corresponde ao total do terreno representado na figura. 0 discurso racional aplicado na resolução da tarefa do item "b" mobiliza conhecimentos matemáticos referentes à noção de área de retângulo associada às relações métricas em um triângulo retângulo. A aplicação dessa técnica mostra a necessidade de conhecer essas relações métricas, identificar e escolher qual deverá ser usada para resolver a tarefa dada.

Discurso tecnológico-teórico $\left[\theta_{15}, \Theta_{15}\right]$ : 0 discurso que fundamenta 0 tipo de técnica da tarefa baseia-se no fato de que um triângulo retângulo possui três alturas relativas, logo, um dos lados desse retângulo pode representar uma altura e o outro lado, a base, sendo possível calcular sua área por meio da fórmula $A=\frac{b . h}{2}$. 0 discurso que fundamenta o tipo de tarefa do item "b" baseia-se no fato de que com base na semelhança de triângulos chegamos às fórmulas das relações métricas utilizadas na resolução deste tipo de tarefa. Nesse sentido, as relações métricas representam o discurso racional e justificativo da técnica utilizada.

0 item "a" da tarefa 15 pode ser resolvido de forma simples; ao girar a imagem, é possível identificar uma base e uma altura. 
Figura 3 - Solução do item "a" da tarefa 15

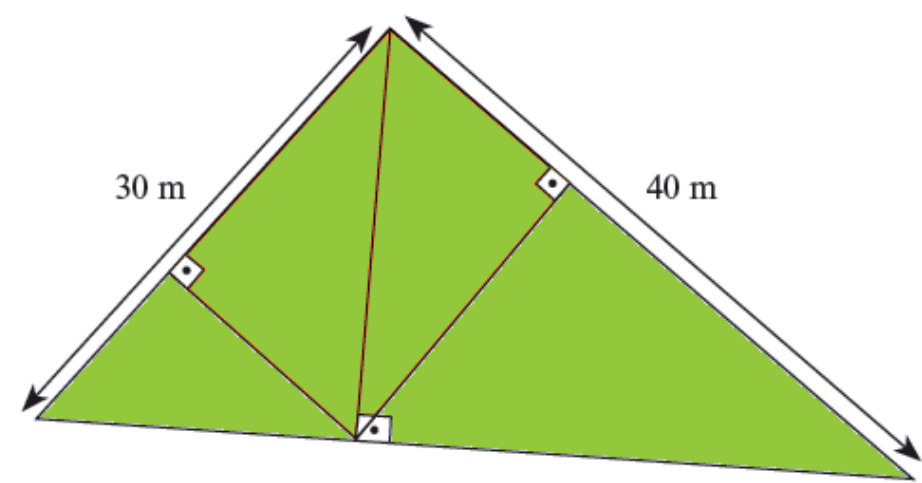

A área do triângulo é:

$\frac{\text { base } \cdot \text { altura }}{2}=\frac{30 \cdot 40}{2}=600 \mathrm{~m}^{2}$

Fonte: Caderno do Professor, 2014, v. 2, p. 33.

Por se tratar de cálculo de área, a escrita da resolução deveria apresentar a palavra área ou a letra "A" antes da fórmula. Sugerimos a utilização da unidade de medida de cada valor na fórmula. 0 ideal é apresentar sempre uma escrita completa para não confundir 0 aluno. Ao efetuar o produto de duas medidas, a unidade aparecerá elevada ao quadrado. Essa confusão referente ao uso das unidades de medidas pode ser um causador dos obstáculos epistemológicos do aluno, segundo Bellemain (2004).

$$
\text { Área do triângulo }=\frac{\text { base } \text {. altura }}{2}=\frac{30 \mathrm{~m} .40 \mathrm{~m}}{2}=600 \mathrm{~m}^{2}
$$

0 item "b" requer uma maior habilidade com os cálculos e seleção das fórmulas a serem utilizadas. É preciso analisar cada situação para saber escolher o melhor caminho a seguir nessa resolução. A Figura 4 mostra a solução encontrada no Caderno do Professor, e a resolução desta tarefa será feita detalhadamente para mostrar a complexidade dessa resolução.

Figura 4 - Solução do item "b" da tarefa 15

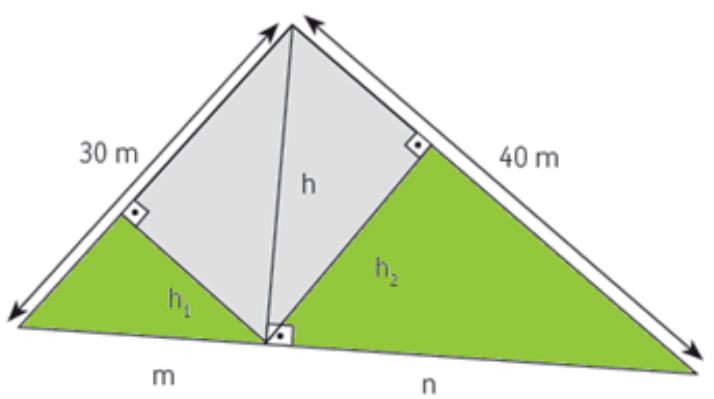

A área da construção será igual a: A = 14,4 ·19,2 = 276,48 m²

Fonte: Caderno do Professor, 2014, v. 2, p. 33 
A região retangular representada tem como lados as alturas h1 e h2 dos dois triângulos, em que 0 triângulo dado é dividido pela altura h relativa à hipotenusa. 0 valor de h pode ser calculado da seguinte maneira:

$$
\text { cateto } x \text { cateto }=\text { hipotenusa } \times \text { altura }
$$

A medida da hipotenusa pode ser calculada pelo Teorema de Pitágoras:

$$
\begin{gathered}
\text { hipotenusa }^{2}=\text { cateto }^{2}+\text { cateto }^{2} \Rightarrow \text { hipotenusa }=\sqrt{\text { cateto }^{2}+\text { cateto }^{2}} \\
\text { hipotenusa }=\sqrt{(30 \mathrm{~m})^{2}+(40 \mathrm{~m})^{2}}=\sqrt{900 \mathrm{~m}^{2}+1600 \mathrm{~m}^{2}}=\sqrt{2500 \mathrm{~m}^{2}}=\mathbf{5 0 ~} \mathbf{m}
\end{gathered}
$$

Voltando ao cálculo de h e substituindo na fórmula, temos:

$$
\begin{gathered}
40 \mathrm{~m} .30 \mathrm{~m}=50 \mathrm{~m} \cdot h \\
1200 \mathrm{~m}^{2}=50 \mathrm{~m} \cdot \mathrm{h} \\
\boldsymbol{h}=\frac{{\mathbf{1 2 0 0 \boldsymbol { m } ^ { 2 }}}^{\mathbf{5 0 m}}=\mathbf{2 4 m}}{\mathbf{5 0 m}}
\end{gathered}
$$

As relações métricas conhecidas permitem calcular diretamente os valores de $\mathrm{m}$ e $\mathrm{n}$ :

$$
\begin{aligned}
& (30 m)^{2}=50 m . m \Rightarrow \mathbf{m}=\frac{900 m^{2}}{50 m}=\mathbf{1 8 m} \\
& (40 m)^{2}=50 m . n \Rightarrow \mathbf{n}=\frac{\mathbf{1 6 0 0 m ^ { 2 }}}{\mathbf{5 0 m}}=\mathbf{3 2 m}
\end{aligned}
$$

Determinando agora $h_{1}$ e $h_{2}$ :

$$
\begin{aligned}
& h \cdot \mathbf{m}=30 \mathrm{~m} \cdot h_{1} \rightarrow h_{1}=\frac{24 m \cdot 18 m}{30 m}=\mathbf{1 4}, \mathbf{4 m} \\
& h \cdot \mathbf{n}=40 \mathrm{~m} \cdot h_{2} \rightarrow h_{2}=\frac{24 m \cdot 32 m}{40 m}=\mathbf{1 9 ,} \mathbf{2 m}
\end{aligned}
$$

A área da construção é calculada pela fórmula da área do retângulo:

$$
A=\text { base } x \text { altura } \rightarrow A=14,4 m \cdot 19,2 m=276,48 \mathrm{~m}^{2}
$$

A área da construção é de 276, $48 \mathrm{~m}^{2}$.

Observa-se que no Caderno do Professor, não são utilizadas as unidades de medidas durante os cálculos, conforme mostra a figura 5 . 
Figura 5 - Cálculos retirados do Caderno do Professor

$$
\begin{aligned}
& 30 \cdot 40=50 \cdot h \rightarrow h=24 \\
& 30^{2}=50 \cdot m \rightarrow m=18 \\
& 40^{2}=50 \cdot n \rightarrow n=32 \\
& h \cdot m=30 \cdot h_{1} \rightarrow h_{1}=14,4 \\
& h \cdot n=40 \cdot h_{2} \rightarrow h_{2}=19,2 \\
& A=14,4 \cdot 19,2=276,48 m^{2}
\end{aligned}
$$

Fonte: Caderno do Professor, 2014, v. 2, p. 33.

As unidades de medidas podem ou não ser escritas junto com os valores numéricos. Acreditamos que a utilização dessas unidades de medidas juntamente com os valores numéricos, facilita na distinção das grandezas associadas à tarefa (área ou perímetro).

\section{ALGUMAS CONSIDERAÇÕES}

Em nossas análises percebemos que ao utilizarmos como aporte teórico a Teoria Antropológica do Didático, a análise das organizações praxeológicas promovidas pelos tipos de tarefas propostas nos Cadernos de Matemática do Aluno e do Professor nos permitiu identificar quais delas têm potencial de influenciar na aprendizagem de área e perímetro em relação aos conteúdos matemáticos, além de estabelecer padrões e práticas de ensino.

Entendemos que os diferentes tipos de tarefas ( $T$ ) apresentadas nos Cadernos de Matemática podem sugerir distintas formas de se trabalharem esses conteúdos matemáticos, por exemplo, 0 aluno pode ser levado a empregar distintas formas de resolução sem que uma seja necessariamente a correta ou única, o que pode ajudar alunos a construir seus conhecimentos e utilizar diversos recursos matemáticos em situações distintas das habituais tratadas em sala de aula. 0 professor deve explorar cada tarefa de acordo com a necessidade de seus alunos, abrir discussões e compartilhar conhecimentos.

Percebemos que os tipos de tarefas T, quando bem apresentadas, podem valorizar diversos conteúdos matemáticos e proporcionar uma melhor abordagem do conteúdo estudado. As análises praxeológicas ajudam a pensar em tipos de técnicas para resolver determinada tarefa e se a técnica escolhida é significativa para a resolução do tipo de tarefa, além de verificar quais conhecimentos (teorias) são necessários para a validação da técnica agregada.

Nesse sentido, destacamos a importância do conteúdo de área e perímetro nos anos finais do Ensino Fundamental, na análise do objeto de pesquisa, tanto do ponto de vista da teoria, quanto como recurso didático utilizado pelos autores desses Cadernos de Matemática, pois a Teoria Antropológica do Didático estuda o homem perante o saber matemático, ou seja, entende o estudo da Matemática dentro do conjunto de atividades humanas e de instituições sociais por meio de interações entre os sujeitos, as instituições e os saberes. 
Quanto à abordagem do objeto de pesquisa (área e perímetro) nos Cadernos de Matemática do Aluno e do Professor analisados, o estudo mostra a importância desse conteúdo no ensino da geometria, da álgebra e da aplicação desse saber no estudo de outros tópicos da Matemática, como: equações do primeiro e segundo graus, operações com polinômios, produtos notáveis, Teorema de Pitágoras, entre outros.

Quanto à análise das organizações matemáticas e das organizações didáticas, permitiu-nos identificar que no estudo do objeto de pesquisa, os autores desses Cadernos de Matemática apresentam esse conteúdo com diferentes abordagens, pois as escolhas didáticas aplicadas na resolução das tarefas contidas nesses Cadernos se diferenciam quanto aos tipos de técnicas (), tecnologias () e teorias (), o que privilegia 0 estudo desse objeto de pesquisa com a aplicação de diferentes tipos de praxeologias pontuais $[\mathrm{T}$,.

Quanto às organizações matemáticas e didáticas, entendemos que são apresentadas de forma clara e bem definidas, e são pertinentes na constituição das praxeologias pontuais aplicadas no estudo de área e perímetro. Quanto às técnicas aplicadas, são elaboradas, fidedignas e confiáveis no cumprimento das tarefas (T) analisadas. Quanto às tecnologias utilizadas nas justificativas dessas técnicas em seus argumentos matematicamente válidos, podem conduzir à elaboração de novas técnicas para resolver essas tarefas, pois, de acordo com a TAD, toda organização praxeológica é formada por um conjunto de técnicas, de tecnologias e de teorias articuladas por objetos ostensivos na resolução de um tipo de tarefa.

Portanto, uma das conclusões que podemos tirar é que a TAD pode ser um instrumento útil a professores para elaboração de suas aulas e entendimento das tarefas propostas a seus alunos, de forma a privilegiar que educandos desenvolvam suas técnicas, utilizem as noções matemáticas de forma a construir conhecimentos e não apenas trabalhar apoiados em repetições que não lhes permitem construir conceitos e nem dispor de, no caso, as noções de áreas e perímetros quando a noção em jogo não é explicita, ou seja, a resolução de uma tarefa não depende de uma aplicação imediata de fórmula.

\section{REFERÊNCIAS}

ALMEIDA, G. A. Polígonos inscritos no círculo: uma abordagem histórico-praxeológica em livros didáticos de Matemática do $9^{\circ}$ ano do Ensino Fundamental. 2012. Dissertação (Mestrado em Educação) - Universidade Federal de Mato Grosso, Cuiabá, 2012.

BALTAR, P.M. Ensegnement et appentissage de la notion d'aire surfasse plane: une étude de acquisition des relations entre longueur et aire au collége.1996. Tese (Doutorado em Didática da Matemática). Universidade Joseph Fourrier, Grenoble, 1996.

BOSCH, M. Um punto de vista antropológico: la evolución de los instrumentos de representación em la atividade Matemática. Anais... IV Simpósio SEIEM. Huelva, 2000.

BOSCH, M.; CHEVALLARD, Y. La sensibiletè de l'activivitè mathématique aux ostensifs. Recherches en Didactique des Mathématiques, 1999.

BRASIL. Ministério da Educação. Base Nacional Comum Curricular: educação é a base: terceira versão. Brasília: MEC, 2017. 
BRITO, A. F. Um estudo sobre a influência do uso de materiais manipulativos na construção do conceito de comprimento como grandeza no $\mathbf{2}^{\mathbf{0}}$ ciclo do Ensino Fundamental. 2003. Dissertação (Mestrado em Educação) - Universidade Federal de Pernambuco, Recife, 2003.

CANNE, D. V. Uma análise praxeológica das tarefas referentes à abordagem de área e perímetro nos anos finais do Ensino Fundamental. 2015. 163 f. Dissertação (Mestrado em Ensino de Ciências e Matemática) - Universidade Cruzeiro do Sul, São Paulo, 2015.

CHEVALLARD, Y. Conceitos Fundamentais da Didática: as perspectivas trazidas por uma abordagem antropológica. In: BRUM, Jean (Org.). Didática das matemáticas. Lisboa: Instituto Piaget, 1996.

CHEVALLARD, Y. Analyse des pratiques enseignantes et didactique des mathématiques: L'approche anthropologique. Actes de I.U.E. de la Rochelle. 1998, p. 91-118.

CHEVALLARD, Y.; BOSCH, M. e GASCÓN, J. Estudar Matemáticas: 0 elo perdido entre 0 ensino e a aprendizagem. Porto Alegre, Artmed Editora, 2001.

FACC0, S.R. Conceito de área: uma proposta de ensino-aprendizagem. 2003. Dissertação (Mestrado em Educação Matemática). PUC - São Paulo, 2003.

FONSECA, L. Relações institucionais: A noção de seno e cosseno na Educação Básica. Anais.. In: Colóquio Internacional: Educação e Contemporaneidade. Sergipe, 2011.

LIMA, P. F.; BELLEMAIN, P.M. B.; Grandezas e medidas. In: CARVALHO, J. B. P. F. (Org) Matemática: Ensino Fundamental. - Brasília : Ministério da Educação, Secretaria de Educação Básica, 2010. 248 p. (Coleção Explorando 0 Ensino; v. 17), p. 167-200

MELO, M. A. P. Um estudo de conhecimentos de alunos de $5^{\mathrm{a}}$ a $8^{\mathrm{a}}$ série do ensino fundamental sobre os conceitos de área e perímetro. 2003. Dissertação (Mestrado em Ensino de Ciências) - Universidade Federal Rural de Pernambuco, 2003.

SANTOS, C.A.B. Formação de professores de Matemática: contribuições de teorias didáticas no estudo da noção de área e perímetro. 2008. Dissertação (Mestrado em Ensino de Ciências e Matemática) - Universidade Cruzeiro do Sul, São Paulo, 2008.

RECEBIDO EM: 23 jul. 2019

CONCLUÍDO EM: 28 fev. 2020 
